\title{
Identification of the targets of hematoporphyrin derivative in lung adenocarcinoma using integrated network analysis
}

Hongtao Yin ${ }^{1}$ and Yan Yu ${ }^{2 *}$

\begin{abstract}
Background: Hematoporphyrin derivative (HPD) has a sensibilization effect in lung adenocarcinoma. This study was conducted to identify the target genes of HPD in lung adenocarcinoma.

Methods: RNA sequencing was performed using the lung adenocarcinoma cell line A549 after no treatment or treatment with X-ray or X-ray + HPD. The differentially expressed genes (DEGs) were screened using Mfuzz package by noise-robust soft clustering analysis. Enrichment analysis was carried out using "BioCloud" online tool. Protein-protein interaction (PPI) network and module analyses were performed using Cytoscape software. Using WebGestalt tool and integrated transcription factor platform (ITFP), microRNA target and transcription factor (TF) target pairs were separately predicted. An integrated regulatory network was visualized with Cytoscape software.

Results: A total of 815 DEGs in the gene set G1 (continuously dysregulated genes along with changes in processing conditions [untreated - treated with X-ray-X-ray + treated with HPD]) and 464 DEGs in the gene set G2 (significantly dysregulated between X-ray + HPD-treated group and untreated/X-ray-treated group) were screened. The significant module identified from the PPI network for gene set G1 showed that ribosomal protein L3 (RPL3) gene could interact with heat shock protein $90 \mathrm{kDa}$ alpha, class A member 1 (HSP90AA1). TFs AAA domain containing 2 (ATAD2) and protein inhibitor of activated STAT 1 (PIAS1) were separately predicted for the genes in gene set G1 and G2, respectively. In the integrated network for gene set G2, ubiquitin-specific peptidase 25 (USP25) was targeted by miR-200b, miR200c, and miR-429.
\end{abstract}

Conclusion: RPL3, HSP9OAA1, ATAD2, and PIAS1 as well as USP25, which is targeted by miR-200b, miR-200C, and miR429, may be the potential targets of HPD in lung adenocarcinoma.

Keywords: Lung adenocarcinoma, Hematoporphyrin derivative, X-ray, Protein-protein interaction network, Integrated network

\section{Background}

Lung/pulmonary adenocarcinoma, a common type of lung cancer, possesses some malignant characteristics such as duct formation, gland formation, and excessive production of mucus [1]. Although smoking is

\footnotetext{
*Correspondence: Yuuny_HTH@hotmail.com

2 Department of Medical Oncology, Harbin Medical University Cancer Hospital, No. 150 Haping Road, Nangang District, Harbin 150081, Heilongjiang, China

Full list of author information is available at the end of the article
}

responsible for most lung adenocarcinoma cases, lung adenocarcinoma is also very common in passive smokers or people with irregular smoking habit $[2,3]$. In the United States, approximately $40 \%$ cases of lung cancer are lung adenocarcinoma, which often originates from the peripheral lung tissue [4] probably because the filters in cigarettes prevent the entry of the bulky grains into the lungs [5]. Although adenocarcinoma produces smaller masses and develops slowly as compared with the other 
types of lung cancers, it is likely to show distant metastasis at an early stage [6]. Therefore, evaluation of the mechanisms underlying lung adenocarcinoma progression is desirable to improve treatment outcomes.

Porphyrins may selective accumulate in malignant tumors [7], and hematoporphyrin derivative (HPD) has been used as a photosensitizer in the photodynamic therapy (PDT) of lung cancer [8]. It was demonstrated that 99mTc-hematoporphyrin-linked albumin nanoparticles (99mTc-HP-ANPs) may be used for the PDT and radiodiagnosis of lung cancer [9]. The combination of PDT and photosensitizers HPD and 5-aminolevulinic acid (ALA) may increase the curative rate for skin cancers, distinctly cut down the photosensitive period, and reduce the dose of pro-toxic HPD [10]. Hematoporphyrin conjugated with the antibodies directed to vascular endothelial growth factor shows high antitumor activities in patients with Lewis lung carcinoma [11]. The expression level of interleukin- 6 affects the cellular sensitivity to PDT, and the combination of PDT and interleukin- 6 may serve as a novel strategy for the therapy of Lewis lung carcinoma [12]. Wang et al. used X-ray as the energy source for PDT activation and suggested that the X-ray-induced photodynamic therapy (X-PDT) may be used as a novel therapeutic method against human cancers [13]. Austerlitz et al. found that the response of the Fricke solution doped with hematoporphyrin and irradiated with lowenergy X-rays was enhanced in PDT [14]. However, the mechanism underlying HPD effects in lung adenocarcinoma are not investigated.

As a commonly studied lung adenocarcinoma cell line, A549 was used as a model in the present study. RNA sequencing was applied to the untreated A549 cells as well as those treated with X-ray or the combination of X-ray and HPD. The differentially expressed genes (DEGs) were screened and enrichment analysis, proteinprotein interaction (PPI) network, and module analyses as well as integrated network analysis were carried out to identify the important genes affected by HPD.

\section{Materials and methods}

\section{Cell cultivation}

The lung adenocarcinoma cell line A549 was acquired from the Cell Bank of Chinese Academy of Sciences. The cells were cultured in Dulbecco's modified Eagle's medium (DMEM) (GIBCO) supplemented with $1 \%$ penicillin/streptomycin double-antibody (GIBCO) and 10\% fetal bovine serum (FBS, GIBCO) in a humidified 5\% $\mathrm{CO}_{2}$ incubator (Thermo) at $37^{\circ} \mathrm{C}$. After the medium was discarded, the cells were washed once with cold phosphate-buffered saline (PBS) and treated with pancreatin (GIBCO) at $37^{\circ} \mathrm{C}$ for $2 \mathrm{~min}$. The suspension was treated with complete medium to neutralize pancreatin, and the mixture was centrifuged (1000 rpm, $5 \mathrm{~min}$ ). The supernatant was discarded and the cells were resuspended in FBS-supplemented DMEM and cultured in a humidified $5 \% \mathrm{CO}_{2}$ incubator (Thermo) at $37^{\circ} \mathrm{C}$.

\section{Cell counting kit-8 (CCK-8) assay}

The cells were counted, seeded into 96-well plates (ABI, $1 \times 10^{4}$ cells/well), and cultured in a humidified $5 \% \mathrm{CO}_{2}$ incubator (Thermo) at $37{ }^{\circ} \mathrm{C}$ overnight. Following incubation, cells were treated with different concentrations of $\operatorname{HPD}(0,2.5,5,10,20,30,60$, and $120 \mu \mathrm{g} / \mathrm{mL})$ and
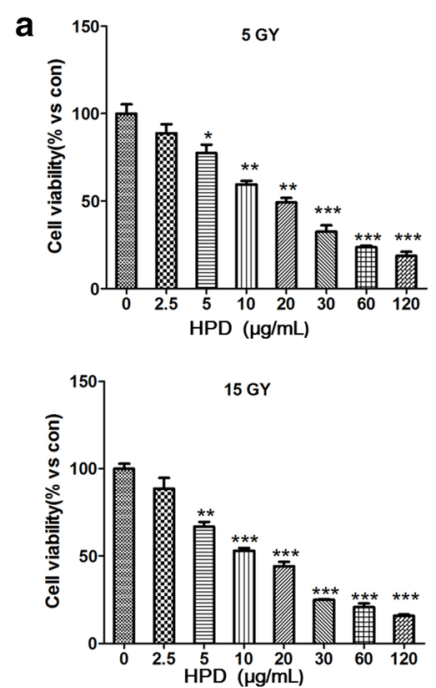
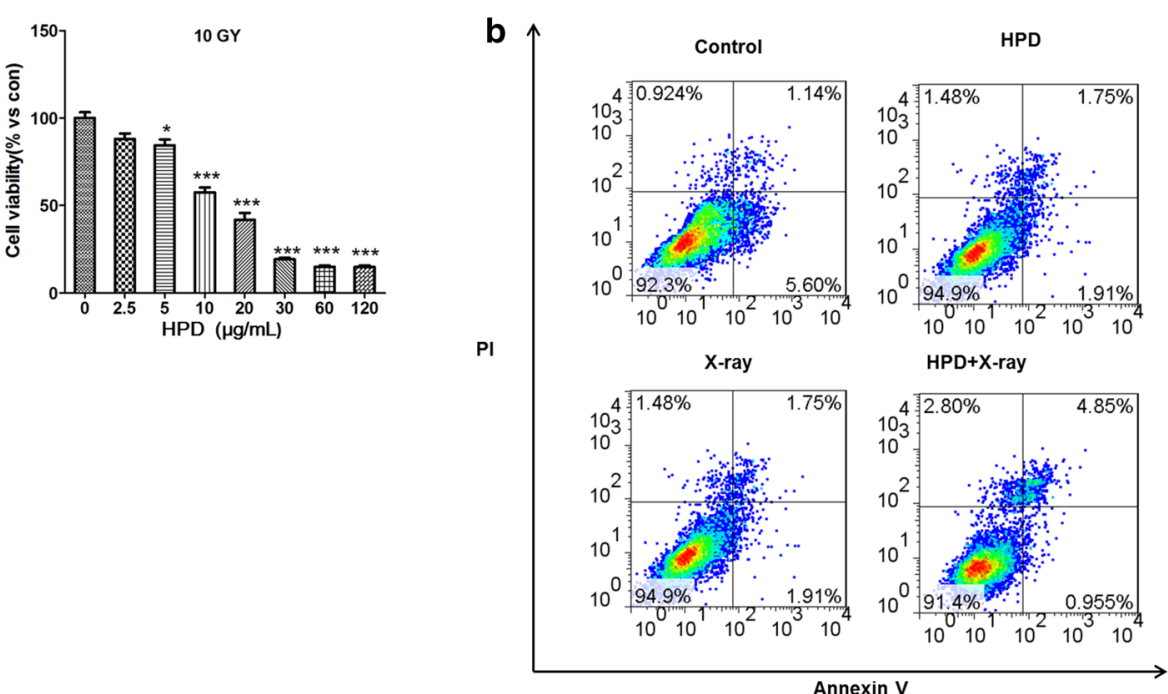

Fig. 1 Effects of the combination of HPD and X-ray. The combination significantly suppressed the proliferation activity (a) and promoted apoptosis of A549 cells (HPD: 10 gg/mL; X-ray: 10 Gy irradiation) (b). HPD hematoporphyrin derivative, Pl propidium iodide 
Table 1 The results of quality control for sequencing data

\begin{tabular}{llllllc}
\hline Sample & Raw reads & Raw base & Clean read & Clean base & $\begin{array}{l}\text { Clean reads rate } \\
\text { (\%) }\end{array}$ & $\begin{array}{l}\text { Clean reads } \\
\text { mean length }\end{array}$ \\
\hline C1_R1 & $23,719,333$ & $3,557,899,950$ & $22,042,930$ & $2,960,605,850$ & 92.93 & 134.3109038 \\
C1_R2 & $23,719,333$ & $3,557,899,950$ & $19,989,260$ & $2,662,625,066$ & 84.27 & 133.2027832 \\
C2_R1 & $34,224,122$ & $5,133,618,300$ & $32,282,452$ & $4,221,477,560$ & 94.33 & 130.766943 \\
C2_R2 & $34,224,122$ & $5,133,618,300$ & $30,870,743$ & $4,017,646,477$ & 90.20 & 130.1441458 \\
C3_R3 & $28,305,868$ & $4,245,880,200$ & $26,491,724$ & $3,503,162,645$ & 93.59 & 132.2361144 \\
C3_R3 & $28,305,868$ & $4,245,880,200$ & $25,565,624$ & $3,364,967,177$ & 90.32 & 131.6207724 \\
H1_R1 & $31,013,406$ & $4,652,010,900$ & $29,028,783$ & $3,809,754,255$ & 93.60 & 131.2405778 \\
H1_R2 & $31,013,406$ & $4,652,010,900$ & $28,211,189$ & $3,695,864,424$ & 90.96 & 131.0070421 \\
H2_R1 & $36,876,370$ & $5,531,455,500$ & $34,583,327$ & $4,464,527,411$ & 93.78 & 129.0947922 \\
H2_R2 & $36,876,370$ & $5,531,455,500$ & $33,557,059$ & $4,323,966,213$ & 91.00 & 128.854147 \\
H3_R1 & $31,602,257$ & $4,740,338,550$ & $29,790,898$ & $3,839,171,450$ & 94.27 & 128.8706185 \\
H3_R2 & $31,602,257$ & $4,740,338,550$ & $28,994,009$ & $3,728,257,975$ & 91.75 & 128.5871842 \\
X1_R1 & $38,506,430$ & $5,775,964,500$ & $36,323,284$ & $4,706,649,914$ & 94.33 & 129.5766626 \\
X1_R2 & $38,506,430$ & $5,775,964,500$ & $35,392,852$ & $4,573,185,587$ & 91.91 & 129.2121242 \\
X2_R1 & $26,676,689$ & $4,001,503,350$ & $24,977,453$ & $3,294,932,070$ & 93.63 & $131.9,162,554$ \\
X2_R2 & $26,676,689$ & $4,001,503,350$ & $23,234,815$ & $3,048,373,656$ & 87.10 & 131.1985336 \\
X3_R1 & $26,125,305$ & $3,918,795,750$ & $24,664,499$ & $3,184,364,078$ & 94.41 & 129.1071867 \\
X3_R2 & $26,125,305$ & $3,918,795,750$ & $23,447,530$ & $3,013,771,864$ & 89.75 & 128.5325944 \\
\hline
\end{tabular}

Table 2 The results of mapping the sequencing data to human genome

\begin{tabular}{|c|c|c|c|c|c|c|}
\hline \multirow[t]{2}{*}{ Sample name } & \multicolumn{2}{|l|}{ Left } & \multicolumn{2}{|l|}{ Right } & \multicolumn{2}{|l|}{ All pair } \\
\hline & Mapped & Uniquely mapped & Mapped & Uniquely mapped & Mapped & Uniquely mapped \\
\hline $\mathrm{C} 1$ & $20,710,400$ & $18,614,230$ & $17,931,401$ & $16,062,833$ & $2,123,508$ & $1,629,067$ \\
\hline $\mathrm{C} 2$ & $29,825,454$ & $26,711,264$ & $27,530,725$ & $24,622,143$ & $3,273,719$ & $2,485,977$ \\
\hline C3 & $24,351,734$ & $22,204,068$ & $23,021,298$ & $21,001,313$ & $2,555,418$ & $1,941,532$ \\
\hline$X 1$ & $33,144,667$ & $29,801,821$ & $31,766,989$ & $28,555,706$ & $3,845,887$ & $2,915,483$ \\
\hline$x 2$ & $23,108,910$ & $20,910,087$ & $20,617,622$ & $18,640,706$ & $2,428,431$ & $1,848,198$ \\
\hline X3 & $22,680,212$ & $20,131,394$ & $20,793,708$ & $18,409,380$ & $2,466,001$ & $1,866,161$ \\
\hline $\mathrm{H} 1$ & $26,599,811$ & $23,805,716$ & $25,426,744$ & $22,751,212$ & $2,999,459$ & $2,248,238$ \\
\hline $\mathrm{H} 2$ & $31,741,919$ & $28,699,363$ & $30,212,029$ & $27,324,878$ & $3,534,230$ & $2,607,919$ \\
\hline $\mathrm{H} 3$ & $27,165,798$ & $24,935,225$ & $25,977,523$ & $23,876,280$ & $2,940,041$ & $2,153,962$ \\
\hline
\end{tabular}

different doses of X-ray $(0,5,10$, and $15 \mathrm{~Gy}$; dose rate was $1 \mathrm{~Gy} / \mathrm{min}$ ) for $24 \mathrm{~h}$. After treatment, the cells were incubated with CCK-8 solution (Tongren; $10 \mu \mathrm{L} /$ well) at $37^{\circ} \mathrm{C}$ for $1 \mathrm{~h}$. The absorbance value of each well was measured with BIV-TEK INSTRUMENTS INC (TECAN) at an optical density (OD) of $450 \mathrm{~nm}$ wavelength, and the cell proliferation activity was calculated.

\section{Flow cytometry assay}

To detect the apoptosis of A549 cells, flow cytometry assay was conducted according to the previously described method [15]. Cells were counted and cultured into six-well plates (ABI, $2 \times 10^{5}$ cells/well) in a humidified $5 \% \mathrm{CO}_{2}$ incubator (Thermo) at $37{ }^{\circ} \mathrm{C}$ overnight. The cells were subsequently treated with different concentrations of HPD and different doses of $\mathrm{X}$-ray. After the medium was discarded, the cells were digested with pancreatin (GIBCO), followed by treatment with fresh medium to deactivate pancreatin and centrifugation (1000 rpm, $6 \mathrm{~min}$ ). The supernatant was discarded and the cells were washed once with PBS and resuspended in $1 \times$ binding buffer (BD Biosciences; $400 \mu \mathrm{L} 1 \times$ binding buffer for the control group and $100 \mu \mathrm{L} 1 \times$ binding buffer for other groups). A total of $100 \mu \mathrm{L}$ of the above solution was transferred into flow tubes and treated with $5 \mu \mathrm{L}$ of fluorescein isothiocyanate (FITC)-Annexin V (BD Biosciences) and $5 \mu \mathrm{L}$ of propidium iodide (PI, BD Biosciences, $50 \mu \mathrm{g} / \mathrm{mL}$ ) (the 



Fig. 2 The clusters $2,3,7,11,13$, and 14 obtained from soft clustering analysis

control group was divided into unstained, Annexin V-stained, PI-stained, and Annexin V+PI-stained groups). After being incubated (in the absence of light) for $15 \mathrm{~min}$ at room temperature, the cells were treated with $400 \mu \mathrm{L}$ of $1 \times$ binding buffer (BD Biosciences) and analyzed with a flow cytometer (BD Biosciences).
RNA extraction and RNA-seq library construction

The cells were counted, seeded into $100 \mathrm{~mm}$ culture dishes $\left(1 \times 10^{6}\right.$ cells/well $)$, and cultured in a humidified $5 \% \mathrm{CO}_{2}$ incubator (Thermo) at $37{ }^{\circ} \mathrm{C}$ overnight. After treatment with different concentrations of HPD or different doses of X-ray (the control group was left 


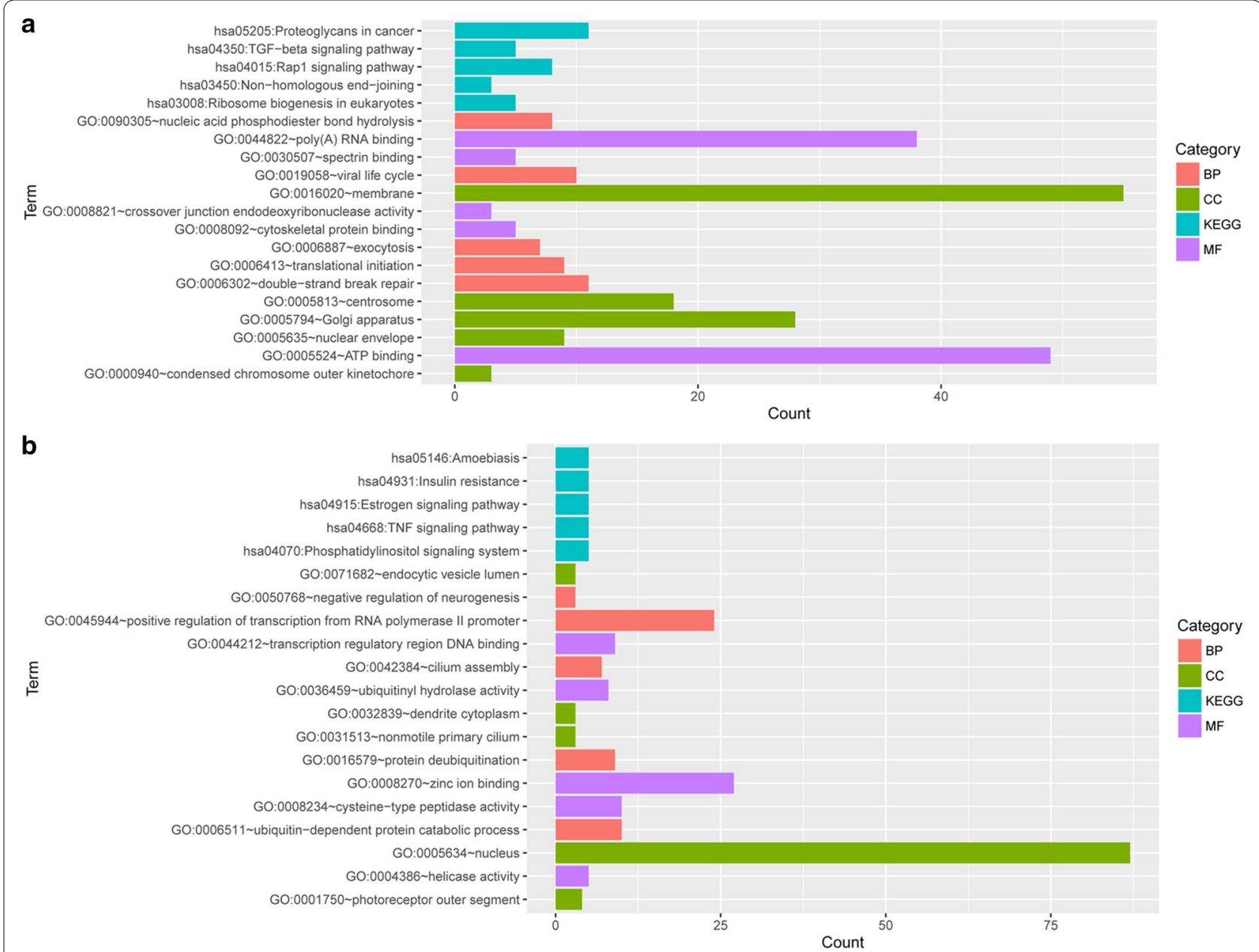

Fig. 3 The top five enriched terms. a Genes in gene set G1 and $\mathbf{b}$ genes in gene set G2. BP biological process, CC cellular component, MF molecular function, KEGG Kyoto Encyclopedia of Genes and Genomes

untreated; the X-ray group was treated with 10 Gy $\mathrm{X}$-ray and cultured for $24 \mathrm{~h}$; X-ray $+\mathrm{HPD}$ group was treated with 10 Gy X-ray $+10 \mu \mathrm{g} / \mathrm{mL}$ of HPD and cultured for $24 \mathrm{~h}$; each group had three replicates), the cells were washed twice with cold PBS. Total RNA was extracted using Trizol reagent (TaKaRa) following the manufacturer's instruction and quantified with a spectrophotometer (Nanodrop). RNA-seq library was constructed with NEBNext ${ }^{\circledR}$ Ultra ${ }^{\text {TM }}$ RNA Library Prep Kit for Illumina ${ }^{\circledR}$ (New England Biolabs) and sequencing was performed on Illumina Hiseq 4000 (PE150) (Illumina). The sequencing data were deposited into the Sequence Read Archive (SRA) database under the accession number of SRP091521.

\section{Data preprocessing and DEG screening}

The Prinseq-lite (http://edwards.sdsu.edu/cgi-bin/prins eq/prinseq.cgi) tool [16] and FASTX_ToolKit (http:// hannonlab.cshl.edu/fastx_toolkit/) [17] were applied for the quality control of the raw data. Barcode and adaptor sequences in the reads were removed. The reads with $\mathrm{N}$ content larger than $5 \%$ were filtered out. Bases with continuous quality under 10 at $5^{\prime}$ or $3^{\prime}$ end were discarded. The reads with low quality (having over $20 \%$ bases with quality lower than 20) and those shorter than $30 \mathrm{nt}$ were removed. The clean reads obtained from the three groups of samples were mapped to GRCH38 human genome using TopHat software (version 2.0.8) [18]. The fragments per kilobase million (FPKM) and read count matrix of the genes were acquired using StringTie tool [19], and gene annotation information was obtained from GENCODE database (version 24, http://genome.imim.es/genco de/) [20]. To identify DEGs, noise-robust soft clustering analysis was performed using the fuzzy c-means clustering algorithm in Mfuzz package (http://www.bioconduct or.org/packages/release/bioc/html/Mfuzz.html) [21]. Specific clusters were selected based on gene expression 


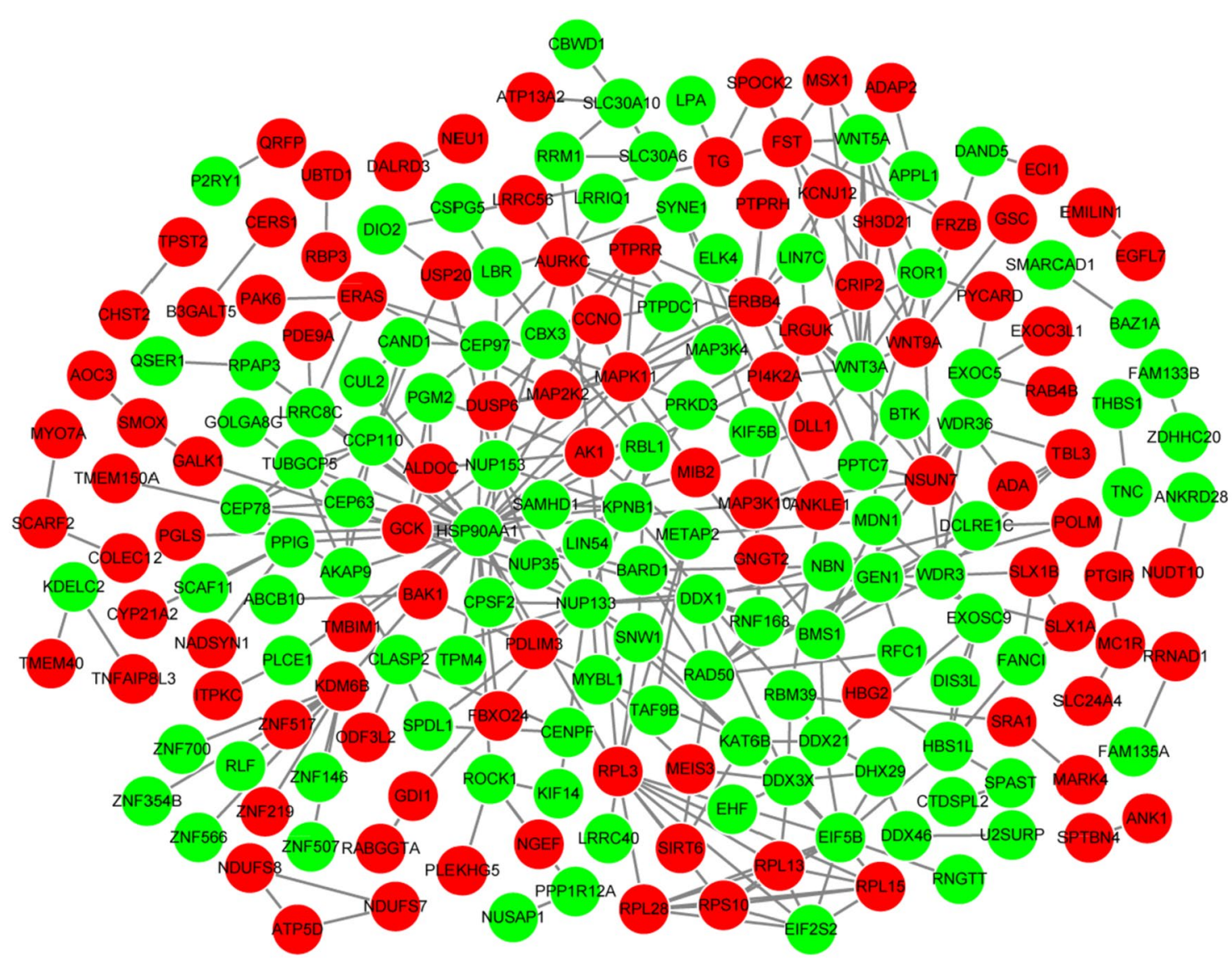

Fig. 4 The protein-protein interaction network constructed for the genes in gene set G1. Red and green circles represent the upregulated and downregulated genes, respectively

trends. Both minSTD and acore parameters were set as 0.5 .

\section{Functional and pathway enrichment analysis}

Gene ontology (GO, http://www.geneontology.org) database can use structured vocabularies for noting genes or gene products from three aspects (MF, molecular function; BP, biological process; and CC, cellular component) [22]. The Kyoto Encyclopedia of Genes and Genomes (KEGG, http://www.genome.ad.jp/kegg) database links genomic information with functional information through the investigation of gene functions [23]. "BioCloud" online tool (http://www.biocloudservice.com) is developed for settling computing problems of high-throughput biological data. Using "BioCloud" online tool, DEGs were subjected to GO functional and KEGG pathway enrichment analyses with the threshold of $p$-value $<0.05$.

\section{PPI network and module analyses}

Search Tool for the Retrieval of Interacting Genes (STRING, http://string-db.org/) is a database that collects the PPIs involving more than 1100 organisms [24]. Based on STRING database [24], the PPIs among the proteins corresponding to DEGs were analyzed with a combined score $>0.4$ as the cut-off criterion. PPI network was subsequently visualized using Cytoscape software (http://www.cytoscape.org) [25], and the hub nodes [26] in the PPI network were screened by calculating their connectivity degrees. Module analysis for PPI network was conducted using the Molecular Complex Detection (MCODE) plugin [27] of Cytoscape software. In addition, enrichment analysis was performed for the nodes of significant modules using "BioCloud" online tool.

\section{Integrated network analysis}

WEB-based gene set analysis toolkit (WebGestalt, http:// www.webgestalt.org) [28] was used to predict the genes involved in the PPI network at $p<0.001$ and the number 




Fig. 5 The protein-protein interaction network constructed for the genes in gene set G2. Red and green circles represent the upregulated and downregulated genes, respectively

of target genes $\geq 4$ as the thresholds. Using Cytoscape software [25], the microRNA (miRNA) target regulatory network was constructed. According to the integrated transcription factor platform (ITFP, http://itfp.biosi no.org/itfp) [29], the transcription factors (TFs) targeting DEGs and the differentially expressed TFs were predicted. The TF target regulatory network was visualized with Cytoscape software [25]. The PPI network, miRNA target regulatory network, and TF target regulatory network were integrated, and an integrated network was constructed with Cytoscape software [25].

\section{Statistical analysis}

One-way analysis of variance and two-tailed $t$-test were applied for statistical analysis using GraphPad prism software (GraphPad Software, San Diego, CA). Data were shown as the mean \pm standard error of the mean (SEM). A value of $p<0.05$ was considered statistically significant.

\section{Results}

Effects of HPD and X-ray on the proliferation and apoptosis of $A 549$ cells

A549 cells were treated with different concentrations of HPD and different doses of X-ray and their proliferation rate was calculated. HPD in combination with X-ray significantly suppressed the proliferation rate of A549 cells $(p<0.05$, Fig. 1a). In particular, $10 \mu \mathrm{g} / \mathrm{mL}$ of HPD and 10 Gy X-ray was the lowest concentration-dose combination that showed significant effects on A549 cell proliferation $(p<0.001)$. A549 cells were treated with $10 \mu \mathrm{g} /$ $\mathrm{mL}$ of HPD and 10 Gy X-ray, and their apoptosis rate was analyzed with flow cytometry. The results of flow cytometry analysis showed that the combination of HPD $(10 \mu \mathrm{g} / \mathrm{mL})$ and X-ray (10 Gy) significantly increased the apoptosis of A549 cells ( $p<0.05$, Fig. 1b). Therefore, the combination of $10 \mu \mathrm{g} / \mathrm{mL}$ of HPD and 10 Gy X-ray was used in the subsequent experiments. 
Table 3 The top 10 nodes in the protein-protein interaction networks constructed for the genes in gene set G1 and the genes in gene set G2

\begin{tabular}{lll}
\hline Gene set & Gene & Degree \\
\hline Gene set G1 & HSP90AA1 & 31 \\
& NUP133 & 13 \\
& EIF5B & 12 \\
MAPK11 & 11 \\
ERBB4 & 10 \\
WNT3A & 10 \\
RPL3 & 10 \\
DDX3X & 9 \\
KDM6B & 9 \\
GCK & 9 \\
XRN1 & 14 \\
HSP90B1 & 13 \\
USP25 & 11 \\
ATM & 8 \\
& EPRS & 7 \\
PIK3CB & 7 \\
NCOA2 & 7 \\
CHD9 & 6 \\
PIAS1 & PIK3R1 & 6 \\
& & 5 \\
\hline
\end{tabular}



Fig. 6 The significant module identified from the protein-protein interaction network constructed for the genes in gene set G1. Red and green circles represent the upregulated and downregulated genes, respectively

\section{Data preprocessing and DEG analysis}

Data sequencing was carried out with quality control (Table 1), and the sequences were mapped to GRCH38 human genome (Table 2). The gene expression matrix was processed with Mfuzz package to reveal a total of 14 clusters (Fig. 2). According to the experimental design, only two types of clusters were selected for analysis. One type of clusters showed continuous upregulation (cluster 2 and 3) or downregulation (cluster 7 and 14) of gene expression along with the change in processing conditions (untreated-treated with X-ray-treated with $\mathrm{X}$-ray + HPD) (containing a total of 815 genes that were included in gene set G1). Another type of cluster included the significantly upregulated (cluster 13) or downregulated (cluster 11) genes under the processing condition of $\mathrm{X}$-ray $+\mathrm{HPD}$ in comparison with the processing condition of untreated and X-ray treatment (containing a total of 464 genes that were included in gene set G2).

\section{Functional and pathway enrichment analysis}

The genes in gene set G1 and G2 were separately subjected to functional and pathway enrichment analyzes. The top five enriched terms in BP, CC, MF, and KEGG categories are shown in Fig. 3. The genes in gene set G1 were mainly enriched in double-strand break repair (BP), membrane (CC), ATP binding (MF), and proteoglycans in cancer (KEGG) (Fig. 3a). The genes in gene set G2 were mainly enriched in positive regulation of transcription from RNA polymerase II promoter (BP), nucleus (CC), zinc ion binding (MF), and estrogen signaling pathway (KEGG) (Fig. 3b).

\section{PPI network and module analyses}

The PPI network constructed for the genes in gene set G1 had 210 nodes and 333 interactions (Fig. 4). On the other hand, the PPI network constructed for the genes in gene set G2 had 135 nodes and 164 interactions (Fig. 5). The top 10 nodes with high degrees in PPI networks are listed in Table 3 and included heat shock protein $90 \mathrm{kDa}$ alpha, class A member $1(H S P 90 A A 1$, degree $=31)$ and ribosomal protein L3 $(R P L 3$, degree $=10)$. Based on MCODE plugin, one significant module was identified from the PPI network constructed for the genes in gene set $\mathrm{G} 1$ that included 13 nodes and 37 interactions (such as HSP90AA1-RPL3) (Fig. 6). The terms enriched for the genes in the module are listed in Table 4, and mainly included translational initiation (BP, $p$-value $=$ translational initiation), cytosol (CC, $p$-value $=1.28 \mathrm{E}-09)$, poly(A) RNA binding (MF, $p$-value $=1.70 \mathrm{E}-06$ ), and ribosome (KEGG, $p$-value $=4.57 \mathrm{E}-06$ ). No significant module was identified from the PPI network constructed for the genes in gene set $\mathrm{G} 2$.

\section{Integrated network analysis}

The miRNAs of the genes implicated in the PPI networks constructed for the genes in gene set G1 (Table 5) and G2 (Table 6) were predicted. The TFs targeting the genes in gene set G1 (ATPase family, AAA domain containing 2 [ATAD2]) and G2 (protein inhibitor of activated STAT 1 [PIAS1]) were also analyzed (Table 7). An integrated network was constructed for the genes in gene set G1 that had 259 nodes (including 25 TFs and 31 miRNAs) and 687 pairs (Fig. 7). The 
Table 4 The terms enriched for the genes in the significant module (only listed terms with $p$-value $<0.01$ )

\begin{tabular}{|c|c|c|c|c|}
\hline Category & Term & Count & P-value & Gene symbol \\
\hline $\mathrm{BP}$ & GO:0006413 translational initiation & 7 & $2.35 \mathrm{E}-10$ & RPL13, RPL15, EIF2S2, RPL3, EIF5B, RPS10, RPL28 \\
\hline $\mathrm{BP}$ & GO:0006412 translation & 7 & $2.20 \mathrm{E}-08$ & RPL13, RPL15, EIF2S2, RPL3, EIF5B, RPS10, RPL28 \\
\hline $\mathrm{BP}$ & GO:0000086 G2/M transition of mitotic cell cycle & 6 & 3.17E-08 & HSP90AA1, TUBGCP5, CCP110, CEP78, AKAP9, CEP63 \\
\hline $\mathrm{BP}$ & GO:0006415 translational termination & 5 & $3.21 \mathrm{E}-07$ & RPL13, RPL15, RPL3, RPS10, RPL28 \\
\hline $\mathrm{BP}$ & GO:0016259 selenocysteine metabolic process & 5 & $3.70 \mathrm{E}-07$ & RPL13, RPL15, RPL3, RPS10, RPL28 \\
\hline $\mathrm{BP}$ & GO:0006414 translational elongation & 5 & $5.47 \mathrm{E}-07$ & RPL13, RPL15, RPL3, RPS10, RPL28 \\
\hline $\mathrm{BP}$ & $\begin{array}{l}\text { GO:0006614 SRP-dependent cotranslational protein } \\
\text { targeting to membrane }\end{array}$ & 5 & $8.12 E-07$ & RPL13, RPL15, RPL3, RPS10, RPL28 \\
\hline $\mathrm{BP}$ & GO:0019083 viral transcription & 5 & $9.41 \mathrm{E}-07$ & RPL13, RPL15, RPL3, RPS10, RPL28 \\
\hline $\mathrm{BP}$ & GO:0001887 selenium compound metabolic process & 5 & $1.01 \mathrm{E}-06$ & RPL13, RPL15, RPL3, RPS10, RPL28 \\
\hline $\mathrm{BP}$ & $\begin{array}{l}\text { GO:0000184 nuclear-transcribed mRNA catabolic pro- } \\
\text { cess, nonsense-mediated decay }\end{array}$ & 5 & $1.20 \mathrm{E}-06$ & RPL13, RPL15, RPL3, RPS10, RPL28 \\
\hline $\mathrm{BP}$ & GO:0019058 viral life cycle & 5 & $3.22 \mathrm{E}-06$ & RPL13, RPL15, RPL3, RPS10, RPL28 \\
\hline $\mathrm{BP}$ & GO:0000278 mitotic cell cycle & 6 & $8.02 \mathrm{E}-06$ & HSP90AA1, TUBGCP5, CCP110, CEP78, AKAP9, CEP63 \\
\hline $\mathrm{BP}$ & GO:0044267 cellular protein metabolic process & 7 & 1.67E-05 & RPL13, RPL15, EIF2S2, RPL3, EIF5B, RPS10, RPL28 \\
\hline $\mathrm{BP}$ & GO:0010467 gene expression & 7 & $2.65 \mathrm{E}-05$ & RPL13, RPL15, EIF2S2, RPL3, EIF5B, RPS10, RPL28 \\
\hline $\mathrm{BP}$ & GO:0006996 organelle organization & 5 & $4.52 \mathrm{E}-05$ & HSP90AA1, CCP110, CEP78, AKAP9, CEP63 \\
\hline $\mathrm{BP}$ & $\begin{array}{l}\text { GO:0034641 cellular nitrogen compound metabolic } \\
\text { process }\end{array}$ & 5 & $6.51 \mathrm{E}-05$ & RPL13, RPL15, RPL3, RPS10, RPL28 \\
\hline $\mathrm{BP}$ & GO:0016032 viral process & 5 & 4.78E-04 & RPL13, RPL15, RPL3, RPS10, RPL28 \\
\hline $\mathrm{BP}$ & GO:0044281 small molecule metabolic process & 6 & $5.11 \mathrm{E}-03$ & HSP90AA1, RPL13, RPL15, RPL3, RPS10, RPL28 \\
\hline $\mathrm{CC}$ & GO:0005829 cytosol & 13 & $1.28 \mathrm{E}-09$ & $\begin{array}{l}\text { HSP9OAA1, TUBGCP5, CCP110, RPL13, CEP78, RPL15, EIF2S2, } \\
\text { RPL3, EIF5B, RPS10, AKAP9, CEP63, RPL28 }\end{array}$ \\
\hline CC & GO:0022625 cytosolic large ribosomal subunit & 4 & 7.57E-06 & RPL13, RPL15, RPL3, RPL28 \\
\hline CC & GO:0005813 centrosome & 5 & $1.28 \mathrm{E}-04$ & TUBGCP5, CCP110, CEP78, AKAP9, CEP63 \\
\hline $\mathrm{CC}$ & GO:0016020 membrane & 5 & $3.24 \mathrm{E}-02$ & HSP90AA1, RPL13, RPL15, RPS10, RPL28 \\
\hline CC & GO:0005840 ribosome & 2 & $3.80 \mathrm{E}-02$ & RPL15, RPS10 \\
\hline MF & GO:0044822 poly(A) RNA binding & 8 & $1.70 \mathrm{E}-06$ & HSP90AA1, RPL13, RPL15, EIF2S2, RPL3, EIF5B, RPS10, RPL28 \\
\hline MF & GO:0003735 structural constituent of ribosome & 5 & $7.88 \mathrm{E}-06$ & RPL13, RPL15, RPL3, RPS10, RPL28 \\
\hline MF & GO:0003723 RNA binding & 5 & $1.47 \mathrm{E}-04$ & RPL13, RPL15, EIF2S2, RPL3, RPL28 \\
\hline MF & GO:0005515 protein binding & 11 & $9.64 \mathrm{E}-03$ & $\begin{array}{l}\text { HSP90AA1, CCP110, RPL13, RPL15, EIF2S2, RPL3, EIF5B, RPS10, } \\
\text { AKAP9, CEP63, RPL28 }\end{array}$ \\
\hline KEGG & hsa03010 ribosome & 5 & 4.57E-06 & RPL13, RPL15, RPL3, RPS10, RPL28 \\
\hline
\end{tabular}

$B P$ biological process, CC cellular component, MF molecular function, KEGG Kyoto Encyclopedia of Genes and Genomes

Table 5 The miRNAs targeted the genes implicated in the protein-protein interaction networks constructed for the genes in gene set G1

\begin{tabular}{lcc}
\hline microRNA & Count & Statistics \\
\hline hsa_TATTATA, MIR-374 & 9 & $p$-value $=1.15 e-05$ \\
hsa_CAGTATT, MIR-200B, MIR-200C, MIR-429 & 11 & -value $=1.92 \mathrm{e}-05$ \\
hsa_GTGCAAT, MIR-25, MIR-32, MIR-92, MIR-363, MIR-367 & $p$-value $=1.00 \mathrm{e}-04$ \\
hsa_CTTTGTA, MIR-524 & 8 & $p$-value $=0.0003$ \\
hsa_GGCACTT, MIR-519E & 5 & $p$-value $=0.0003$ \\
hsa_CTACTGT, MIR-199A & 6 & $p$-value $=0.0003$ \\
hsa_GCAAGGA, MIR-502 & 4 & $p$-value $=0.0004$ \\
hsa_TGTTTAC, MIR-30A-5P, MIR-30C, MIR-30D, MIR-30B, MIR-30E-5P & $p$-value $=0.0005$ \\
hsa_TGAATGT, MIR-181A, MIR-181B, MIR-181C, MIR-181D & 10 & $p$-value $=0.0006$ \\
hsa_TGCTGCT, MIR-15A, MIR-16, MIR-15B, MIR-195, MIR-424, MIR-497 & 9 & $p$-value $=0.0007$ \\
hsa_TACTTGA, MIR-26A, MIR-26B & 10 & $p$-value $=0.0007$ \\
hsa_ATGTCAC, MIR-489 & 7 & $p$-value $=0.0008$ \\
\hline
\end{tabular}


Table 6 The miRNAs targeted the genes implicated in the protein-protein interaction networks constructed for the genes in gene set $\mathbf{G 2}$

\begin{tabular}{|c|c|c|}
\hline microRNA & Count & Statistics \\
\hline hsa_CAGTATT, MIR-200B, MIR-200C, MIR-429 & 13 & $p$-value $=1.27 \mathrm{e}-09$ \\
\hline hsa_CATTTCA, MIR-203 & 10 & $p$-value $=1.29 \mathrm{e}-08$ \\
\hline hsa_TACTTGA, MIR-26A, MIR-26B & 8 & $p$-value $=2.86 \mathrm{e}-06$ \\
\hline hsa_ATGTACA, MIR-493 & 8 & $p$-value $=4.11 \mathrm{e}-06$ \\
\hline hsa_AAGCACT, MIR-520F & 7 & $p$-value $=6.53 \mathrm{e}-06$ \\
\hline hsa_ATTCTTT, MIR-186 & 7 & $p$-value $=1.56 \mathrm{e}-05$ \\
\hline hsa_GCTGAGT, MIR-512-5P & 4 & $p$-value $=1.69 \mathrm{e}-05$ \\
\hline hsa_GTACAGG, MIR-486 & 4 & $p$-value $=2.43 \mathrm{e}-05$ \\
\hline hsa_AAAGGGA, MIR-204, MIR-211 & 6 & $p$-value $=4.87 e-05$ \\
\hline hsa_TGCTGCT, MIR-15A, MIR-16, MIR-15B, MIR-195, MIR-424, MIR-497 & 9 & $p$-value $=6.55 \mathrm{e}-05$ \\
\hline hsa_TGGTGCT, MIR-29A, MIR-29B, MIR-29C & 8 & $p$-value $=1.00 \mathrm{e}-04$ \\
\hline hsa_ATGTTTC, MIR-494 & 5 & $p$-value $=1.00 \mathrm{e}-04$ \\
\hline hsa_GTGCAAT, MIR-25, MIR-32, MIR-92, MIR-363, MIR-367 & 6 & $p$-value $=0.0003$ \\
\hline hsa_CTGTTAC, MIR-194 & 4 & $p$-value $=0.0003$ \\
\hline hsa_CTATGCA, MIR-153 & 5 & $p$-value $=0.0004$ \\
\hline hsa_ACTGTAG, MIR-139 & 4 & $p$-value $=0.0005$ \\
\hline hsa_CTGAGCC, MIR-24 & 5 & $p$-value $=0.0006$ \\
\hline
\end{tabular}

Table 7 The transcription factors (TFs) targeting the genes in gene set $\mathbf{G 1}$ and gene set $\mathbf{G} 2$

\begin{tabular}{|c|c|c|c|}
\hline \multicolumn{2}{|c|}{ G1 gene list } & \multicolumn{2}{|c|}{ G2 gene list } \\
\hline TF & Count & TF & Count \\
\hline RNGTT & 14 & TRIM23 & 7 \\
\hline RPAP3 & 13 & NCOA2 & 6 \\
\hline ATAD2 & 10 & PHC3 & 4 \\
\hline ZNF146 & 6 & SYNJ1 & 4 \\
\hline NUP133 & 5 & CHD9 & 3 \\
\hline METAP2 & 4 & PIAS1 & 3 \\
\hline RBL 1 & 4 & $B A Z 2 B$ & 2 \\
\hline DDX3X & 3 & EPRS & 2 \\
\hline KLHL24 & 3 & MRPS12 & 2 \\
\hline PTBP2 & 3 & PSME4 & 2 \\
\hline$B A Z 1 A$ & 2 & $P W W P 2 B$ & 2 \\
\hline CAND1 & 2 & MIERI & 1 \\
\hline MDN1 & 2 & TCF12 & 1 \\
\hline SARDH & 2 & TTC3 & 1 \\
\hline WDR36 & 2 & ZBTB33 & 1 \\
\hline BIN2 & 1 & ZNF292 & 1 \\
\hline DDX46 & 1 & ZNF593 & 1 \\
\hline$N B N$ & 1 & & \\
\hline OSBPL11 & 1 & & \\
\hline RFC1 & 1 & & \\
\hline$R L F$ & 1 & & \\
\hline SAMHD1 & 1 & & \\
\hline WDR3 & 1 & & \\
\hline ZNF507 & 1 & & \\
\hline
\end{tabular}

integrated network for the genes in gene set G2 was also visualized; it carried 174 nodes (including $18 \mathrm{TFs}$ and 32 miRNAs) and 445 pairs (Fig. 8). In particular, ubiquitin-specific peptidase 25 (USP25) was targeted by $m i R-200 b, m i R-200 c$, and $m i R-429$ in the integrated network for the genes in gene set $\mathrm{G} 2$. The top 30 nodes with high degrees in the integrated networks are listed in Table 8.

\section{Discussion}

In this study, the CCK-8 assay result revealed the significant suppression in the proliferation activity of A549 cells in response to the treatment with the combination of HPD and X-ray. The combination of $10 \mu \mathrm{g} / \mathrm{mL}$ of HPD and 10 Gy X-ray was selected as the lowest concentration/dose that achieved a significant increase in the apoptosis of A549 cells, which might be a limitation in terms of analysis of the data. In Europe, hematoporphyrin is the most commonly used photosensitizer for the treatment of advanced lung cancer [30, 31]. Previous studies have demonstrated that HPD-PDT may inhibit proliferation and induce apoptosis of A549 cells, thereby inducing effective killing of adenocarcinoma cells [32, 33]. After the optimization of the combination treatment of HPD and X-ray, a series of bioinformatic analyses were performed with the RNA-seq data.

Through noise-robust soft clustering analysis, 815 genes that showed continuous upregulated or downregulated expression along with the change in processing conditions (untreated-treated with X-ray-treated 


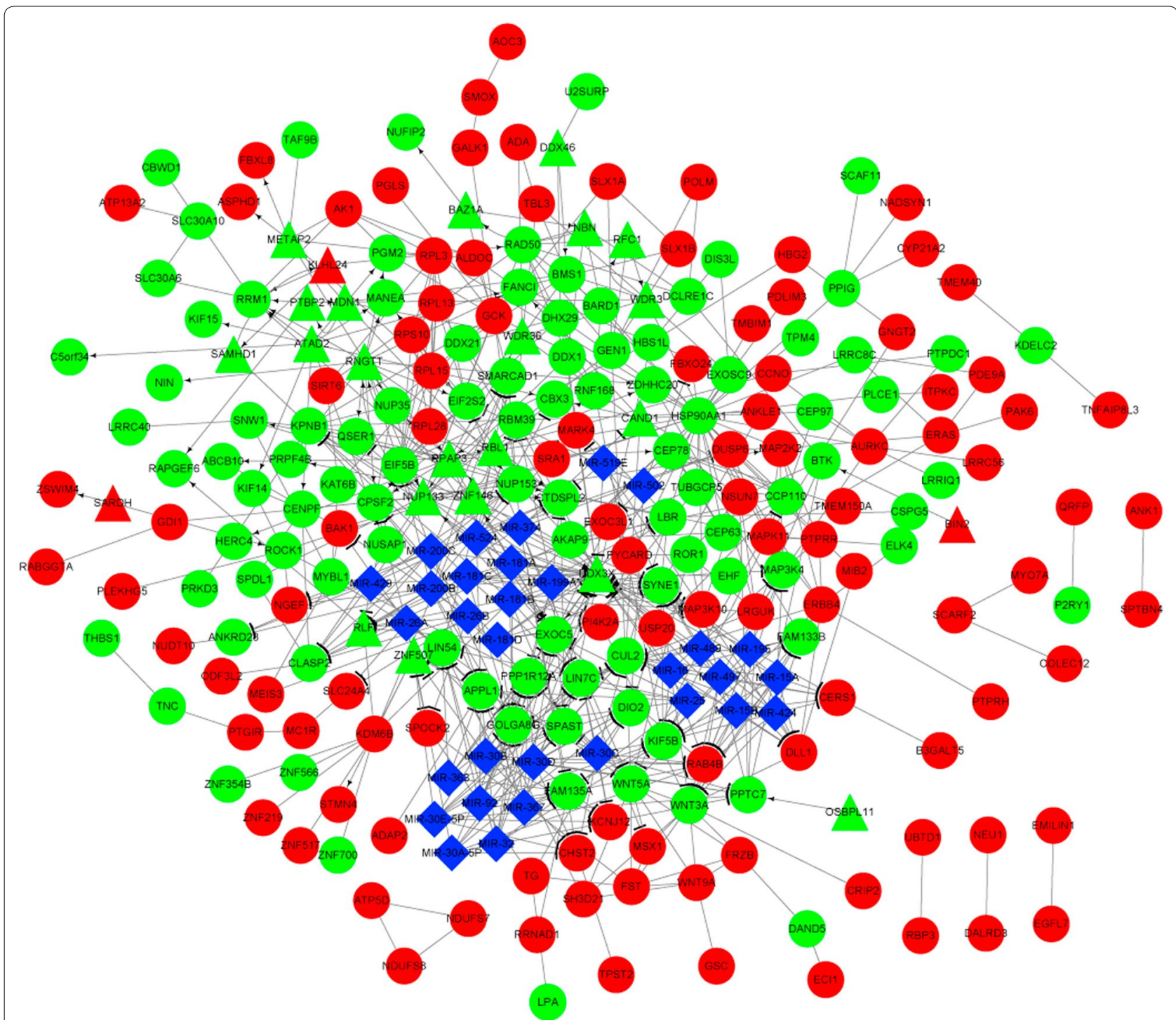

Fig. 7 The integrated network constructed for the genes in gene set G1. Red and green separately indicate the upregulated and downregulated genes, respectively. Circles and triangles represent genes and transcription factors, respectively. Blue diamonds indicate miRNAs

with X-ray + HPD) were included in the gene set G1. A total of 464 genes that were significantly upregulated or downregulated under the processing condition of X-ray + HPD were included in the gene set G2. The significant module identified from the PPI network constructed for the genes in gene set G1 revealed the interaction between RPL3 and HSP9OAA1. RPL3 functions in the response of cells to oxaliplatin- and 5 -fluorouracil-induced nucleolar stress and may be used to improve the therapeutic effects of these drugs against cancers [34]. The chemotherapy curative effect of actinomycin D is determined by RPL3 status in cancers shorting of $p 53$; thus, high level of RPL3 may be useful for the treatment of lung and colon cancers [35].
The frequencies of mutant genotypes of HSP90AA1, $H S P 90 A B 1$, and HSP9OB1 are reported to be significantly higher in the patients with non-small cell lung cancer (NSCLC) in the Turkish population [36]. Downregulation of HSP90 expression correlated with increased overall survival of patients with NSCLC, and HSP90 inhibitor exerts an antiproliferative effect on NSCLC cell lines [37, 38]. These observations suggest that RPL3 interacting with HSP90AA1 may be associated with the sensibilization effect of HPD in lung adenocarcinoma.

ATAD2 and PIAS1 were separately predicted as the TFs targeting the genes from the gene sets G1 and G2. Caron et al. demonstrated that ATAD2 overexpression 




Fig. 8 The integrated network constructed for the genes in gene set G2. Red and green separately indicate the upregulated and downregulated genes, respectively. Circles and triangles indicate genes and transcription factors, respectively. Blue diamonds indicate miRNAs

may promote the malignant transformation of lung and breast cancers by affecting the basic properties of chromatin [39]. Wang et al. found that ATAD2/AAA ${ }^{+}$nuclear coregulatory cancer associated $(A N C C A)$ may serve as a promising biomarker for the treatment and prognosis of squamous cell lung carcinoma [40]. PIAS1 contributes to cytoplasm-nuclear distribution of focal adhesion kinase by interacting with it, and focal adhesion kinase activity in the nucleus facilitates survival and progression of NSCLC via promotion of DNA repair regulation and cellextracellular matrix interaction [41, 42]. PIAS1 mediates oncogenic signaling by promoting promyelocytic leukemia (PML) degradation, and PIAS1 and PML expression is negatively correlated in NSCLC cell lines [43]. Therefore, ATAD2 and PIAS1 may be involved in the action mechanism of HPD in lung adenocarcinoma.

In the integrated network for the genes in the gene set G2, USP25 was targeted by $m i R-200 \mathrm{~b}, \mathrm{miR}$ $200 c$, and $m i R-429$. $m i R-200 c$ may serve as a tumor suppressor in NSCLC through the inhibition of USP25 expression and may be applied for therapeutic purposes [44]. The overexpression of $m i R-200 c$ and $m i R$ 141 is associated with the short overall survival of patients with lung adenocarcinoma via angiogenesis and mesenchymal-epithelial transition [45]. The low expression of $m i R-200 b$ is reported to induce E2F transcription factor 3 overexpression and increase the chemoresistance of patients with lung adenocarcinoma to docetaxel [46]. Zhu et al. suggested that the serum levels of $m i R-29 c$ and $m i R-429$ may be used as non-invasive biomarkers for patients with early stage NSCLC [47]. Lang et al. found that miR-429 contributes to cell proliferation and metastasis and regulates several tumor suppressor genes in patients with NSCLC, serving as a possible therapeutic target [48]. These observations suggest that USP 25 targeted by $m i R-200 b$, $m i R-200 c$, and $m i R-429$ may also function in the action process of HPD in lung adenocarcinoma. 
Table 8 The top 30 nodes with higher degrees in the integrated networks for gene set $\mathrm{G} 1$ and gene set $\mathrm{G} 2$

\begin{tabular}{|c|c|c|c|}
\hline \multicolumn{2}{|c|}{ G1 gene list } & \multicolumn{2}{|c|}{ G2 gene list } \\
\hline Node & Degree & Node & Degree \\
\hline DDX3X & 34 & SYNJ1 & 25 \\
\hline HSP9OAA1 & 31 & USP25 & 23 \\
\hline NUP133 & 21 & TBL1XR1 & 21 \\
\hline RPAP3 & 19 & NCOA2 & 20 \\
\hline RNGTT & 17 & PIK3R1 & 18 \\
\hline WNT3A & 16 & XRN1 & 18 \\
\hline SYNE1 & 15 & CHD9 & 17 \\
\hline EIF5B & 15 & $B A Z 2 B$ & 17 \\
\hline GOLGA8G & 14 & PIAS1 & 16 \\
\hline KIF5B & 14 & ATRX & 14 \\
\hline EXOC5 & 14 & ARHGAP5 & 14 \\
\hline WNT5A & 13 & MIR-200B & 13 \\
\hline PPP1R12A & 13 & MIR-200C & 13 \\
\hline CUL2 & 13 & MIR-429 & 13 \\
\hline LINTC & 13 & HSP9OB1 & 13 \\
\hline NUP153 & 12 & WDFY3 & 12 \\
\hline$R A B 4 B$ & 12 & TRIM23 & 12 \\
\hline MIR-200B & 11 & INSIGI & 11 \\
\hline CTDSPL2 & 11 & ATM & 11 \\
\hline$R L F$ & 11 & SEPT2 & 11 \\
\hline APPL1 & 11 & MIR-203 & 10 \\
\hline MIR-200C & 11 & PSME4 & 10 \\
\hline MIR-429 & 11 & EIF3A & 10 \\
\hline PPTC7 & 11 & ZMYM2 & 10 \\
\hline MIR-30B & 11 & EPRS & 10 \\
\hline KPNB1 & 11 & CNOT6 & 9 \\
\hline MAPK11 & 11 & ATF2 & 9 \\
\hline EIF2S2 & 10 & MIR-15A & 9 \\
\hline CLASP2 & 10 & MIR-16 & 9 \\
\hline DLL1 & 10 & MIR-15B & 9 \\
\hline
\end{tabular}

\section{Conclusion}

A total of 815 DEGs in gene set G1 were identified along with a change in processing conditions (untreated-treated with X-ray-treated with $\mathrm{X}$-ray $+\mathrm{HPD})$. In addition, 464 DEGs in gene set G2 were screened under the processing condition of $\mathrm{X}$-ray + HPD. RPL3, HSP90AA1, ATAD2, as well as PIAS1 and USP25, which is targeted by miR-200b, $m i R-200 c$, and $m i R-429$ may show correlations with the sensibilization effect of HPD in lung adenocarcinoma. Further validation with experimental research is warranted to confirm the roles of these genes in the sensibilization effect of HPD in lung adenocarcinoma.

\section{Highlights}

1. In the significant module for gene set G1, RPL3 could interact with $H S P 90 A A 1$.

2. ATAD2 and PIAS1 were the transcription factors separately targeting the gene set $\mathrm{G} 1$ and $\mathrm{G} 2$.

3. In the integrated network, $m i R-200 b, m i R-200 c$, and miR-429 co-regulated USP25.

\section{Abbreviations}

HPD: hematoporphyrin derivative; DEGs: differentially expressed genes; PPI: protein-protein interaction; ITFP: integrated transcription factor platform; TF: transcription factor; PDT: photodynamic therapy; X-PDT: X-ray-induced photodynamic therapy; DMEM: Dulbecco's modified Eagle's medium; PBS: phosphate-buffered saline; CCK-8: cell counting kit-8; FITC: fluorescein isothiocyanate; FPKM: fragments per kilobase million.

\section{Authors' contributions}

HY carried out the conception and design of the research, participated in the acquisition of data, and drafted the manuscript. YY carried out the analysis and interpretation of data, participated in the study design, and performed statistical analyses. Both authors read and approved the final manuscript.

\section{Author details}

${ }^{1}$ Department of Radiation Oncology, Harbin Medical University Cancer Hospital, Harbin 150081, Heilongjiang, China. ${ }^{2}$ Department of Medical Oncology, Harbin Medical University Cancer Hospital, No. 150 Haping Road, Nangang

District, Harbin 150081, Heilongjiang, China.

\section{Acknowledgements}

Not applicable.

\section{Competing interests}

The authors declare that they have no competing interests.

\section{Availability of data and materials}

The sequencing data were deposited into the Sequence Read Archive (SRA) database under the Accession Number of SRP091521.

\section{Consent for publication}

Not applicable.

\section{Ethics approval and consent to participate}

This study was approved by Ethics Committee of Harbin Medical University Cancer Hospital.

Funding

None.

\section{Publisher's Note}

Springer Nature remains neutral with regard to jurisdictional claims in published maps and institutional affiliations.

Received: 7 September 2018 Accepted: 16 January 2019

Published online: 04 February 2019

\section{References}

1. Lortet-Tieulent J, Soerjomataram I, Ferlay J, Rutherford M, Weiderpass E, Bray F. International trends in lung cancer incidence by histological subtype: adenocarcinoma stabilizing in men but still increasing in women. Lung Cancer. 2014;84(1):13-22. 
2. Ahrendt SA, Decker PA, Alawi EA, Zhu YR, Sanchez-Cespedes M, Yang SC, Haasler GB, Kajdacsy-Balla A, Demeure MJ, Sidransky D. Cigarette smoking is strongly associated with mutation of the K-ras gene in patients with primary adenocarcinoma of the lung. Cancer. 2001;92(6):1525-30.

3. Rivera GA, Wakelee H. Lung cancer in never smokers. Oxygen Transport Tissue XXXIII. 2016;893(10):43-57.

4. Mcguire S. World Cancer Report 2014. Geneva, Switzerland: World Health Organization, International Agency for Research on Cancer, WHO Press, 2015. Adv Nutr. 2016; 7(2):418

5. Marugame T, Sobue T, Nakayama T, Suzuki T, Kuniyoshi H, Sunagawa K, Genka K, Nishizawa N, Natsukawa S, Kuwahara O. Filter cigarette smoking and lung cancer risk; a hospital-based case-control study in Japan. Br J Cancer. 2004:90(3):646-51.

6. Verdu M, Trias I, Roman R, Rodon N, Pubill C, Calvo M, Garcia-Pelaez B, Diaz O, Puig X. EGFR mutations in lung cancer: a morphological, immunohistochemical and molecular study of lung adenocarcinoma. Revista Española De Patología. 2016;49(4):226-33.

7. Fh F, Gs W, Lo M. Cancer detection and therapy; affinity of neoplastic, embryonic, and traumatized tissues for porphyrins and metalloporphyrins. Proc Soc Exp Biol Med Soc Exp Biol Med. 1948;68(3):640.

8. Li W, Yang J, Zheng S, Wen J, Zhai M, Liu Y. The study of comparing the efficiency of ZnPc-PDT and HPD-PDT in killing mice lewis lung cancer cells. Ifmbe Proc. 2013;39:1644-7.

9. Yang SG, Chang JE, Shin B, Park S, Na K, Shim CK. 99mTc-hematoporphyrin linked albumin nanoparticles for lung cancer targeted photodynamic therapy and imaging. J Mater Chem. 2010;20(41):9042-6.

10. Wang $Y$, Lin $Y$, Zhang HG, Zhu J. A photodynamic therapy combined with topical 5-aminolevulinic acid and systemic hematoporphyrin derivative is more efficient but less phototoxic for cancer. J Cancer Res Clin Oncol. 2016;142(4):1-9.

11. Novichenko NL, Mamchur AA, Lisniak IO, Gamaliya MF. Study of photodynamic efficiency of the hematoporphyrin conjugated with antibody to VEGF in mouse Lewis carcinoma. Exp Oncol. 2008;30(4):315-8.

12. Usuda J, Okunaka T, Furukawa K, Tsuchida T, Kuroiwa Y, Ohe Y, Saijo N, Nishio K, Konaka C, Kato H. Increased cytotoxic effects of photodynamic therapy in IL-6 gene transfected cells via enhanced apoptosis. Int J Cancer. 2001;93(4):475-80.

13. Wang GD, Nguyen HT, Chen H, Cox PB, Wang L, Nagata K, Hao Z, Wang A, $\mathrm{Li} Z$, Xie J. X-ray induced photodynamic therapy: a combination of radiotherapy and photodynamic therapy. Theranostics. 2016;6(13):2295-305.

14. Austerlitz C, Souza VLBD, Campos DMT, Kurachi C, Bagnato V, Sibata C. Enhanced response of the Fricke solution doped with hematoporphyrin under X-rays irradiation. Braz Archiv Biol Technol. 2008;51 (2):271-9.

15. Lutsenko GV. Flow-cytometry assay for apoptosis using fluorophor 10-N-nonyl acridine orange. Biochem Suppl. 2010;4(4):349-57.

16. Schmieder R, Edwards R. Quality control and preprocessing of metagenomic datasets. Bioinformatics. 2011;27(27):863-4.

17. Krueger F, Kreck B, Franke A, Andrews SR. DNA methylome analysis using short bisulfite sequencing data. Nat Methods. 2012;9(2):145-51.

18. Kim D, Pertea G, Trapnell C, Pimentel H, Kelley R, Salzberg SL. TopHat2: accurate alignment of transcriptomes in the presence of insertions, deletions and gene fusions. Genome Biol. 2013;14(4):R36.

19. Pertea M, Pertea GM, Antonescu CM, Chang TC, Mendell JT, Salzberg SL. Stringtie enables improved reconstruction of a transcriptome from RNAseq reads. Nat Biotechnol. 2015;33(3):290-5.

20. Harrow J, Frankish A, Gonzalez JM, Tapanari E, Diekhans M, Kokocinski F, Aken BL, Barrell D, Zadissa A, Searle S. GENCODE: the reference human genome annotation for The ENCODE Project. Genome Res. 2012;22(9):1760-74.

21. Futschik ME, Carlisle B. Noise-robust soft clustering of gene expression time-course data. J Bioinform Comput Biol. 2005;3(4):965-88.

22. Consortium TGO. Gene Ontology Consortium: going forward. Nucl Acids Res. 2015;43(Database issue):1049-56.

23. Kanehisa M, Sato Y, Kawashima M, Furumichi M, Tanabe M. KEGG as a reference resource for gene and protein annotation. Nucleic Acids Res. 2015:44(D1):D457-62.

24. Franceschini A, Szklarczyk D, Frankild S, Kuhn M, Simonovic M, Roth A, Lin J, Minguez P, Bork P, von Mering C. STRING V9. 1: protein-protein interaction networks, with increased coverage and integration. Nucleic Acids Res. 2013;41(D1):D808-15
25. Saito R, Smoot ME, Ono K, Ruscheinski J, Wang P-L, Lotia S, Pico AR, Bader GD, Ideker T. A travel guide to Cytoscape plugins. Nat Methods. 2012;9(11):1069-76.

26. Liu X, Wang Y, Zhao D, Zhang W, Shi L. Patching by automatically tending to hub nodes based on social trust. Comput Stand Interf. 2016;44:94-101.

27. Bader GD, Hogue CW. An automated method for finding molecular complexes in large protein interaction networks. BMC Bioinform. 2003:4:2.

28. Wang J, Duncan D, Shi Z, Zhang B. WEB-based GEne SeT AnaLysis Toolkit (WebGestalt): update 2013. Nucleic Acids Res. 2013;41(W1):77-83.

29. Zheng G. ITFP: an integrated platform of mammalian transcription factors. Bioinformatics. 2008;24(20):2416-7.

30. Almeida RD, Manadas BJ, Carvalho AP, Duarte CB. Intracellular signaling mechanisms in photodynamic therapy. Biochem Biophys Acta. 2004;1704(2):59.

31. Dougherty TJ. An update on photodynamic therapy applications. J Clin Laser Med Surg. 2002;20(1):3-7.

32. Yang ZZ, Li MY, Xiang DB, Dai N, Zeng LL, Li ZP, Wang G, Wang D. Knock down of the dual functional protein apurinic/apyrimidinic endonuclease 1 enhances the killing effect of hematoporphyrin derivative-mediated photodynamic therapy on non-small cell lung cancer cells in vitro and in a xenograft model. Cancer Sci. 2010;101(1):180.

33. Xia L, Guan W, Wang D, Zhang YS, Zeng LL, Li ZP, Wang G, Yang ZZ. Killing effect of Ad5/F35-APE1 siRNA recombinant adenovirus in combination with hematoporphyrin derivative-mediated photodynamic therapy on human nonsmall cell lung cancer. Biomed Res Int. 2013;2013(4):957913.

34. Esposito D, Crescenzi E, Sagar V, Loreni F, Russo A, Russo G. Human rpL3 plays a crucial role in cell response to nucleolar stress induced by 5 -FU and L-OHP. Oncotarget. 2014;5(22):11737-51.

35. Russo A, Pagliara V, Albano F, Esposito D, Sagar V, Loreni F, Irace C, Santamaria R, Russo G. Regulatory role of rpL3 in cell response to nucleolar stress induced by Act D in tumor cells lacking functional p53. Cell Cycle. 2015;15(1):41-51.

36. Coskunpinar E, Akkaya N, Yildiz P, Oltulu YM, Aynaci E, Isbir T, Yaylim I. The significance of HSP90AA1, HSP90AB1 and HSP90B1 gene polymorphisms in a Turkish population with non-small cell lung cancer. Anticancer Res. 2014;34(2):753-7.

37. Ruiz MIG, Floor K, Roepman P, Rodriguez JA, Meijer GA, Mooi WJ, Jassem E, Niklinski J, Muley T, Van Zandwijk N. Integration of gene dosage and gene expression in non-small cell lung cancer, identification of HSP90 as potential target. PLoS ONE. 2008;3(3):e1722.

38. Sequist LV, Gettinger S, Senzer NN, Martins RG, Jänne PA, Lilenbaum R, Gray JE, lafrate AJ, Katayama R, Hafeez N. Activity of IPI-504, a novel heat-shock protein 90 inhibitor, in patients with molecularly defined non-small-cell lung cancer. J Clin Oncol. 2010;28(33):4953-60.

39. Caron C, Lestrat C, Marsal S, Escoffier E, Curtet S, Virolle V, Barbry P, Debernardi A, Brambilla C, Brambilla E. Functional characterization of ATAD2 as a new cancer/testis factor and a predictor of poor prognosis in breast and lung cancers. Oncogene. 2010;29(37):5171-81.

40. Wang D, Pan Y, Hao T, Chen Y, Qiu S, Chen L, Zhao J. Clinical and prognostic significance of ANCCA in squamous cell lung carcinoma patients. Arch Med Res. 2016;47(2):89-95.

41. Constanzo JD, Tang KJ, Rindhe S, Melegari M, Liu H, Tang X, RodriguezCanales J, Wistuba I, Scaglioni PP. PIAS1-FAK interaction promotes the survival and progression of non-small cell lung cancer. Neoplasia. 2016;18(5):282-93.

42. Constanzo JD, Rabellino A, Konstantinidou S, Scaglioni K. The SUMO ligase PIAS1 promotes the progression and survival of solid tumors of different histopathological origins. Int J Media Manag. 2003;14(1):316.

43. Rabellino A, Carter B, Konstantinidou G, Wu SY, Rimessi A, Byers LA, Heymach JV, Girard L, Chiang CM, Teruya-Feldstein J. The SUMO E3-ligase PIAS1 regulates the tumor suppressor PML and its oncogenic counterpart PML-RARA. Cancer Res. 2012;72(9):2275-84.

44. Jing L, Qiang T, Yan M, Lei L, Lin H, Zhao F, Bao G, Kong H, Chao G, Zhang F. miRNA-200c inhibits invasion and metastasis of human non-small cell lung cancer by directly targeting ubiquitin specific peptidase 25 . Mol Cancer. 2014;13(1):207-12.

45. Tejero R, Navarro A, Campayo M, Viñolas N, Marrades RM, Cordeiro A, Ruízmartínez M, Santasusagna S, Molins L, Ramirez J. miR-141 and miR-200c as markers of overall survival in early stage non-small cell lung cancer adenocarcinoma. PLoS ONE. 2014;9(7):e101899. 
46. Feng B, Wang R, Song HZ, Chen LB. MicroRNA-200b reverses chemoresistance of docetaxel-resistant human lung adenocarcinoma cells by targeting E2F3. Cancer. 2012;118(13):3365-76.

47. Zhu W, He J, Chen D, Zhang B, Xu L, Ma H, Liu X, Zhang Y, Le H. Expression of miR-29c, miR-93, and miR-429 as potential biomarkers for detection of early stage non-small lung cancer. PLOS ONE. 2014;9(2):e87780.
48. Lang Y, Xu S, Ma J, Wu J, Jin S, Cao S, Yu Y. MicroRNA-429 induces tumorigenesis of human non-small cell lung cancer cells and targets multiple tumor suppressor genes. Biochem Biophys Res Commun. 2014;450(1):154-9.
Ready to submit your research? Choose BMC and benefit from:

- fast, convenient online submission

- thorough peer review by experienced researchers in your field

- rapid publication on acceptance

- support for research data, including large and complex data types

- gold Open Access which fosters wider collaboration and increased citations

- maximum visibility for your research: over 100M website views per year

At BMC, research is always in progress.

Learn more biomedcentral.com/submissions 